\title{
Chances and Battles in Stroke Research
}

\author{
Charles P. Warlow \\ Department of Clinical Neurosciences, Western General Hospital, Edinburgh, UK
}

\section{Key Words}

Mentoring $\cdot$ Regulation

\section{Abstract}

Here I have reviewed how good luck, bad luck and barriers determined my research directions in stroke over the last 30 or so years. Good luck should be exploited, and very often barriers can be not just overcome but put to good use as well. It is crucial for the young researcher to find mentors as good as I have had, and to move around to gain a broad experience, and for the experienced researchers to bring on the younger generation as I have tried to do.
\end{abstract}

Copyright $\odot 2007$ S. Karger AG, Basel

Some things happen just by chance. They seem to be completely accidental. They may represent good luck or bad luck. You can exploit a lucky chance, like Alexander Fleming when he discovered the penicillin mould which had inhibited bacterial growth on his Petri dish, or not. Other things seem to be just bad luck, an unhappy chance, or sometimes they are not chance events at all but somehow deliberate - either way they may require an effort, a battle even, to get them sorted out because they are really important and worthwhile, even if there are barriers to be overturned. Or, more satisfying, bad luck can be turned to one's advantage, as we shall see. (c) 2007 S. Karger AG, Basel

$1015-9770 / 07 / 0244-0391 \$ 23.50 / 0$

Fax +41613061234

E-Mail karger@karger.ch

www.karger.com
Accessible online at:

www.karger.com/ced

\section{Early Prestroke Years}

With chance in mind I thought it would be of interest to reflect on my mostly good luck and occasional bad luck, and the barriers, that have directed my efforts in stroke research, although my first lucky chance happened long before I got interested in stroke. In my first year after qualification as a doctor I had failed to get the job I really wanted, and so I arrived at my second choice, the Birmingham Accident Hospital, to be called - in the first hour of my first day - to a child with a rather mild burn having an epileptic seizure. The nurses said this often happened to children with burns, which was a surprise to me and seemed to have been ignored by the plastic surgeons. So I discussed the case with the only other person in the hospital interested in medicine (rather than trauma surgery and burns) - Pam Hinton, who was a medical registrar - and we quickly found 5 similar cases in the next few months, wrote them up although we could not explain the pathophysiology which underlay what was clearly sometimes fatal cerebral oedema, and our paper - my very first - was published in the Lancet in 1969 [1]. A lucky chance had led me to a burns unit and a case that I followed up, with - very importantly - the willing help of a more experienced senior colleague. I also realised for the first time the general truth that many conditions which are first thought to be rare and commonly fatal turn out to be much more common once they are recognised, and are in truth rarely fatal.

Prof. Charles P. Warlow

Department of Clinical Neurosciences, Western General Hospital

Crewe Road

Edinburgh EH4 2XU (UK)

Tel. +44 131537 2082, Fax +44 131332 5150, E-Mail charles.warlow@ed.ac.uk 


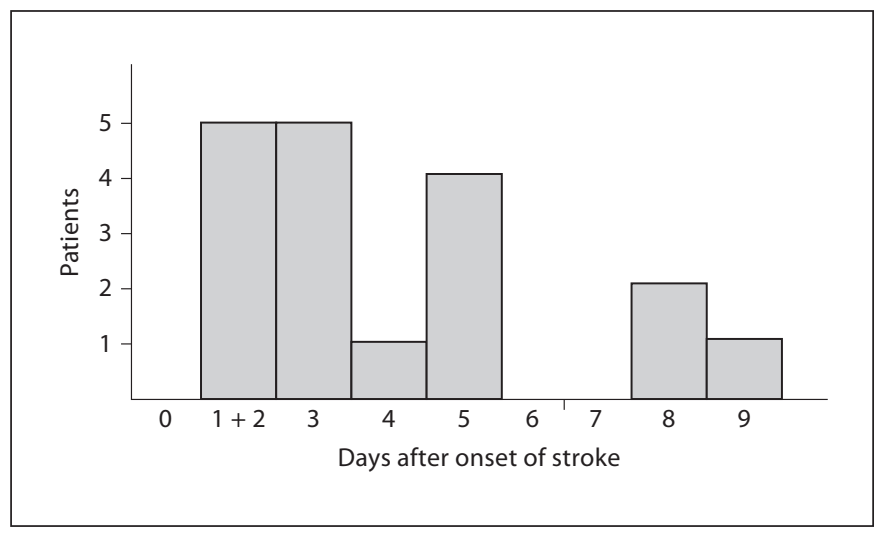

Fig. 1. DVT in the legs after stroke onset. A prospective study of 30 patients using iodine-125 fibrinogen leg scanning. Days between onset of stroke and leg vein thrombosis. From [2].

\section{Stumbling into Stroke Research}

The next lucky chance was responsible for my research career in stroke. I, and most of my generation of medical students, had taken absolutely no notice of stroke; the stroke patients in London were generally diverted from our elitist teaching hospitals to long-stay repositories in the days before geriatricians really existed. But in 1971, I got a job as a Lecturer in Medicine at the University of Aberdeen in the north of Scotland where Stuart Douglas, the Professor of Medicine, said to me - 'well, you want to be a neurologist, but we are interested in thrombosis, you had better do some stroke research'. So I did, just like that, although I took the easy option of working on deep venous thrombosis (DVT) of the legs in hemiplegic stroke patients rather than the much harder and longer-term work which was really needed on arterial thrombosis. We drew attention to the very high frequency of DVT using iodine-125 fibrinogen to detect very small thrombi forming in the calf muscles, often within a couple of days of the stroke onset [2] (fig. 1), and always in the paralysed leg; in fact, this stroke complication had first been described in 1810 by Ferriar [3], which reminded me of one of my favourite quotations, from Murphy, the first novel by Samuel Beckett: 'The sun shone, having no alternative, on the nothing new' [4]. Along the way I did my first randomised trial, of heparin to prevent DVT in acute myocardial infarction [5], and learnt a lot about platelets and the effect of aspirin on them, which had only been discovered a few years earlier. All this was the result of a lucky chance, without any real planning at all - or any bad luck or battles in those early days. But then I had won- derful mentors and supervisors in Aberdeen who taught me (without explicitly saying so) that to get the best out of people you guide them to do what they want to do in the context of what you want them to do, and then let them get on with it, providing the support - in resources and other help - required to do the job, and giving them the credit when the job is done.

For the next few years I trained back in London to be a neurologist and did little research, but in 1976 I moved to Oxford where again I found myself with a wonderful mentor in Bryan Matthews who was quietly supportive and let me develop my own research programme. At first I thought to look at platelet behaviour in stroke but, once again, mere chance turned me in another direction. I had arrived in Oxford at the same time as an old friend, Klim McPherson, who introduced me to the epidemiologists, led by the late Richard Doll. I knew no epidemiology at all, although I think someone tried to teach me about drains and epidemics at medical school, but the Oxford epidemiology was not like that. The young statistician Richard Peto was exhorting the whole world to gather larger sample sizes in clinical trials, the ex-obstetrician Iain Chalmers was dreaming of what was to become the Cochrane Collaboration, the mathematician Peter Smith taught me how to do case-control studies, Martin Vessey was working on the vascular complications of oral contraceptives, and Leo Kinlen on leukaemia clusters near nuclear power stations - it all seemed so much more interesting than test tubes, rats and molecules. And so I was hooked, and over the next 10 years in Oxford we got going on three major research projects, which still rumble on to this present day.

\section{The United Kingdom Transient Ischaemic Attack Aspirin Trial and Early Meta-Analysis}

The first was an obvious one and sprang from my earlier interest in platelets and aspirin, the United Kingdom Transient Ischaemic Attack Aspirin Trial which - with Richard Peto - we made more or less the largest trial of an antiplatelet drug at the time [6]. In fact, it was the first multicentre trial in British neurology, an achievement I put down to knowing a lot of neurologists in the country because I had moved around during my training, unlike - very sadly - the modern specialist trainee in the UK who tends to get stuck just in one place, in part because so often, unlike in my day, he or she now has to take into consideration the career aspirations of a partner who can't just be dragged from one end of the country to an- 
Fig. 2. The United Kingdom Transient Ischaemic Attack Aspirin Trial: interim results. Forest plot showing various outcomes of interest, both aspirin dose groups together versus placebo, odds ratios with 95\% confidence intervals. From [6], reprinted with permission.

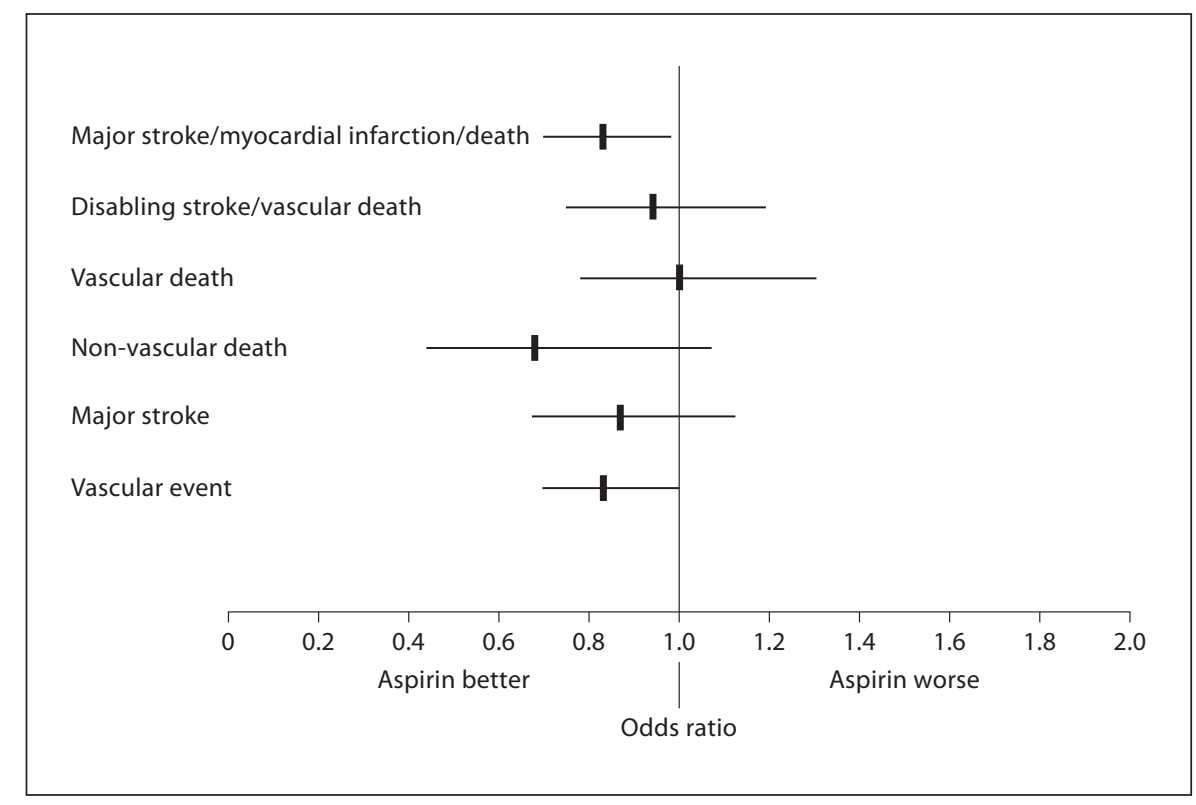

other, but also because our modern training system encourages uniformity, a serious lack of imagination, and geographical ossification. Curiously, the most impressive result of the aspirin trial we thought at the time was a chance effect, a $42 \%$ relative reduction in cancer deaths from $2.6 \%$ in the placebo group to $1.5 \%$ in the aspirin group. The effect of aspirin on our primary outcome of stroke, myocardial infarction and vascular death was far less impressive (fig. 2), an $18 \%$ relative odds reduction with a rather wide $95 \%$ confidence interval, despite recruiting over 2,000 patients, from $31 \%$ to a miserable $2 \%$. So miserable that we wrote 'Having spent nearly 10 years designing, funding, conducting and analysing this study, we are frustrated to conclude that its results cannot stand alone. The best estimate of the true effects of antiplatelet treatment... is that which comes from a proper overview of all the important relevant trial evidence and not by undue emphasis on one particular trial result' - metaanalysis had come to the rescue, developed as it happened mostly in Oxford by Richard Peto and Iain Chalmers at the very time we were ruminating over the aspirin trial result. So in the same issue of the British Medical Journal as the aspirin trial appeared in 1988 came the first outpouring of what was then known as the Antiplatelet Trialists' Collaboration [7], explaining in some detail the new statistical technique of meta-analysis, and systematically reviewing all 25 published randomised controlled trials of antiplatelet treatment, mostly aspirin then, in about 30,000 high vascular risk patients. This showed (fig. 3) a reduction in the odds of a serious vascular event of $25 \%$ with a tight and highly convincing $95 \%$ confidence interval from about 19 to $31 \%$.

\section{The European Carotid Surgery Trial}

The second research project arose naturally out of the aspirin trial because in the early 1980s many UK neurologists, certainly those involved in the trial, had become seriously concerned whether carotid endarterectomy did any good at all, almost no randomised trials had been done, and I and others wrote a series of articles questioning the operation which appeared in one issue of Stroke in 1984 [8]. It made sense to start a randomised controlled trial of carotid endarterectomy. But very soon it became clear that we could not possibly achieve the required sample size just in the UK so that is why we expanded into Europe in what became known as the European Carotid Surgery Trial (ECST), and that is how I personally came to meet and become friends with so many European neurologists. However, by then, the lucky chances that led me into stroke and then epidemiology and then into clinical trials were beginning to be accompanied by a few barriers - at the time most UK neurologists were interested only in diagnosis and not treatment, vascular surgeons were suspicious of neurologists and the European countries were not as well disposed towards each other as they are now, although by this time the Eu- 


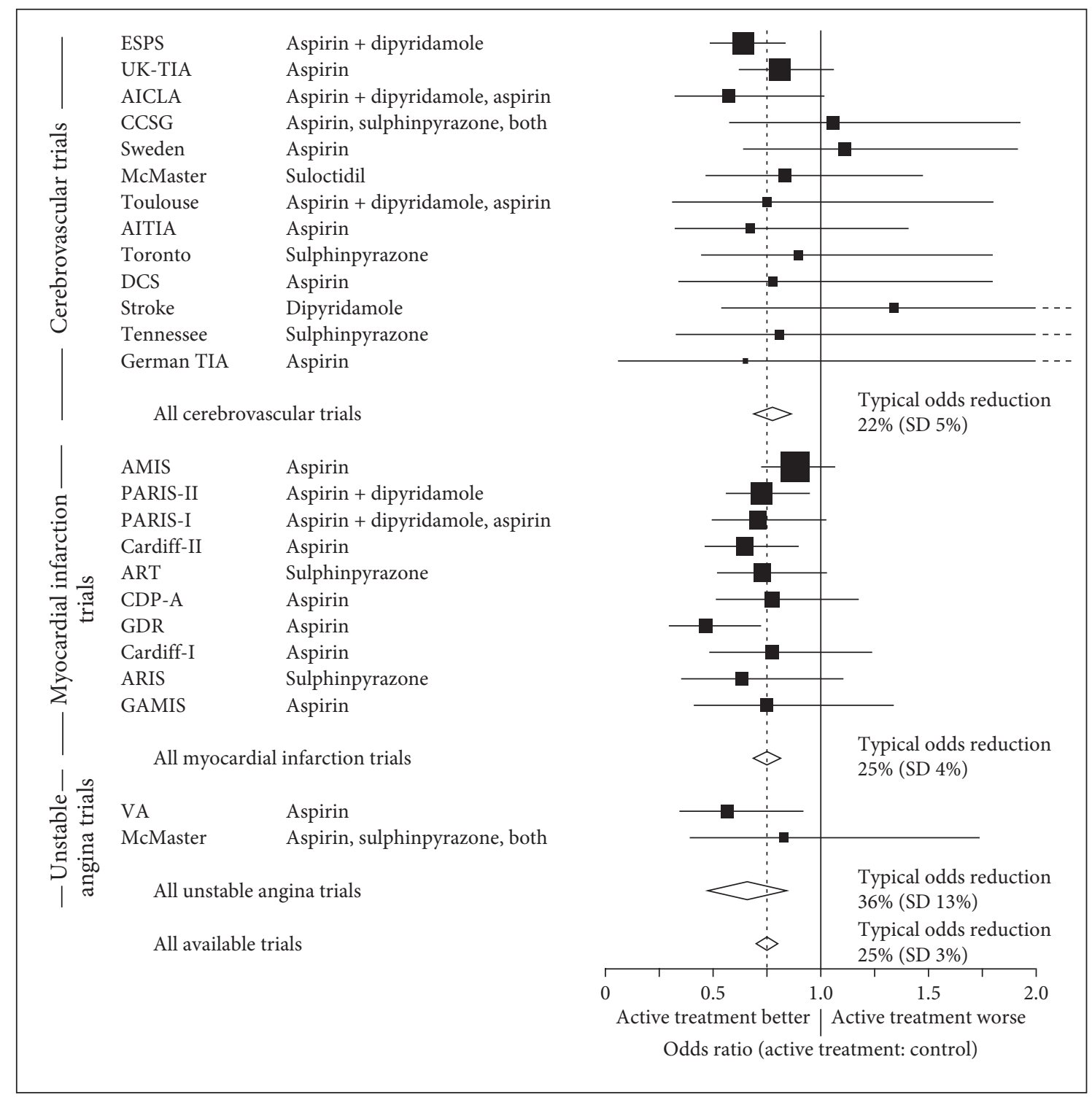

Fig. 3. Secondary prevention of vascular disease by prolonged antiplatelet treatment; the first results of the Antiplatelet Trialists' Collaboration. A meta-analysis with each trial odds ratio represented by a box, the size of which is proportional to the amount of outcome information provided by that trial, and with a horizontal line representing the $99 \%$ confidence interval. The diamonds represent the pooled results of several trials, their width being their $95 \%$ confidence interval. The outcomes are all patients with 'stroke, myocardial infarction and vascular death'. From [7], reprinted with permission.

ropean Union was becoming well established, and importantly for the trial so was pan-European funding for science (ethics barriers were still in the future).

We did consider expanding the ECST into North America but thought that the Americans would never properly contribute to a trial they were not running themselves, so Henry Barnett from London, Ontario, who was on our ECST Data Monitoring Committee, set up the
North American Symptomatic Carotid Endarterectomy Trial (NASCET), and that really was an extreme stroke of luck. Why?

(1) Because it generated friendly competition between the two trials to recruit lots of patients and do a better trial - in the end both trials were in my view equally good although ours was much simpler and cheaper. 

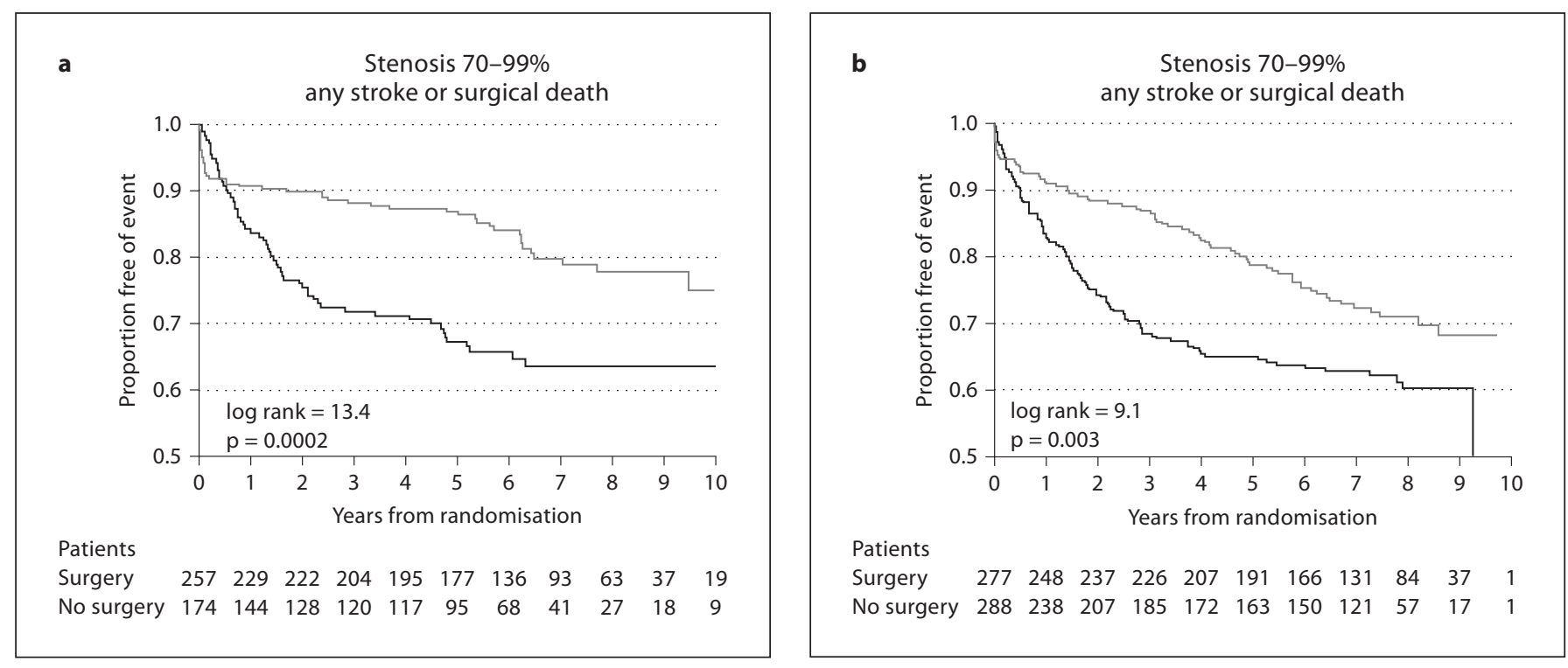

Fig. 4. The Kaplan-Meier curves of the ECST (a) compared with the NASCET (b) for patients with 70-99\% (NASCET) stenosis; outcome of any stroke or surgical death.

(2) Because the methods and results were so similar (fig. 4), we could put the two trials together in a metaanalysis and so effectively double our sample size.

(3) More importantly than 1 and 2, hypotheses generated in one trial could be tested in the other trial, because it contained a completely independent data set.

It was number 2 and 3, the meta-analysis, that Pete Rothwell rose to fame on, having started as research fellow on the ECST in Edinburgh in 1991 with a plastic ruler to measure stenosis on catheter angiograms, before moving to Oxford in 1996, via a short spell with Henry Barnett in Canada. From his efforts, and the earlier work by Graeme Hankey, who was with us in the early 1990s before rising to fame in his native Australia, arose our interest in how to target preventive treatments on the relatively small number of patients who definitely need them, not the much larger number who might need them - in other words reducing the number needed to treat.

\section{The Oxfordshire Community Stroke Project}

The third research effort was the Oxfordshire Community Stroke Project (OCSP), a register of all possible strokes and transient ischaemic attacks in a population of about 100,000 people in Oxfordshire in the 1980s with, I must admit, not a very clear idea of what we were going to do with it when we started. I just thought it was a good

Chances and Battles in Stroke Research

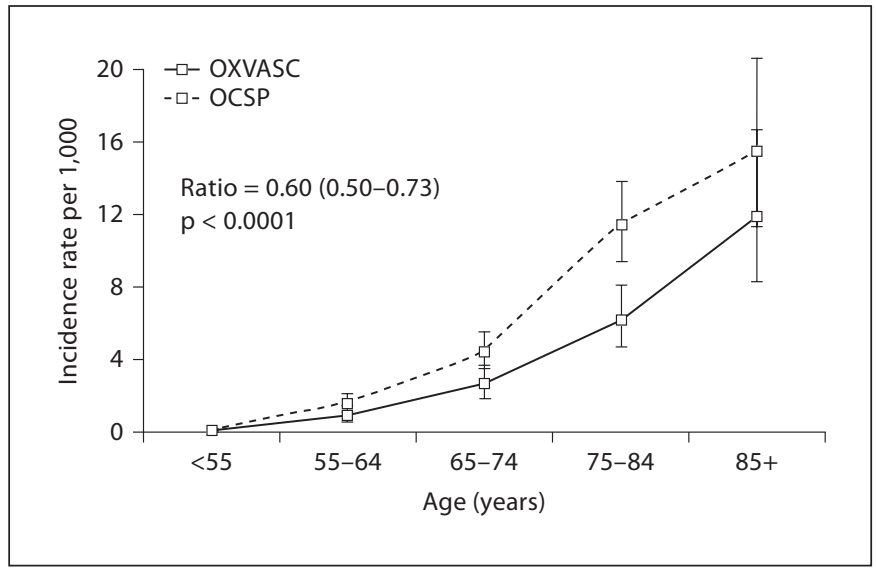

Fig. 5. Incidence by age of non-minor stroke in 2002-2004 (OXVASC) versus 1981-1984 (OCSP), in the same Oxfordshire population. From [9], reprinted with permission.

idea at the time, and something would come of it if we recruited some bright and inquisitive research fellows. And so it did, first with Peter Sandercock, then John Bamford, then Martin Dennis, and then John Burn, picking up Allan House, a psychiatrist, and Ian Starkey, a cardiologist, along the way. Although there was of course some planning involved, the good luck was to have attracted these people who were responsible for the success the OCSP became. And, although it may not have looked 
like it, it really was complete chance that 20 years later Pete Rothwell found himself in Oxford and thought what a good idea it would be to look again at the incidence of stroke in the same population 20 years after the OCSP, using the same methodology. I did not deliberately insert him into Oxford, and certainly not with any plan to do his Oxford Vascular Study (OXVASC), which remarkably showed that stroke incidence had declined by about $40 \%$ in 20 years [9] (fig. 5).

\section{The Edinburgh Stroke Research Group}

By the time all this was going on, I had made my final move, back to Scotland and to Edinburgh, in 1987. This was not chance it seems, strangely it was preordained. Years earlier, when I was a very junior doctor looking after a lady in an infectious diseases ward, she offered to tell my fortune. She told me that I would become a Professor in a northern country. I said, 'you mean somewhere like Norway, or would Scotland count?' 'Yes', she said, 'Scotland would count'.

In Edinburgh, my task was not so much to set up new research projects but to attract senior researchers and get them up, running, and independent. This did require an effort, it certainly couldn't be left to chance. Peter Sandercock and Martin Dennis were persuaded to come to Edinburgh. Peter Sandercock then set up the huge International Stroke Trial of aspirin and heparin, took on the Editorship of the Stroke Review Group of the Cochrane Collaboration, and is now running the 3rd International Stroke Trial, of intravenous thrombolysis in acute ischaemic stroke. Martin Dennis, a geriatrician not a neurologist, set up what we like to think is the best comprehensive stroke service in the UK within which he - and we - could embed any number of clinical research projects, mostly concentrating on the complications of stroke, including my old interest of DVT of the legs. Graeme Hankey arrived from the Mayo Clinic and worked on predicting outcome in transient ischaemic attack patients. Joanna Wardlaw emerged from her radiology training programme in Edinburgh and has since become one of the most prominent stroke radiologists in the world. Richard Lindley arrived from Newcastle upon Tyne, stayed a few years, worked on the International Stroke Trials, and then emigrated to Sydney. A little later, Cathie Sudlow, still training in general medicine at the time, reviewed the methodology and outcome of stroke incidence studies worldwide and after working with Richard Peto in Oxford returned to Edinburgh to work on the epidemiology and genetics of stroke. Rustam AlShahi Salman arrived to work on what has become his own personal niche of intracranial vascular malformations. Myles Connor from Johannesburg, who has just published the first systematic review of all that is known of stroke in Sub Saharan Africa, has now moved to Edinburgh, and Malcolm Macleod, a local graduate, joined our stroke research group to work on systematic reviews of animal experiments in stroke. And, crucially, embedded with us we have always had a statistician, first Jim Slattery and then Steff Lewis. Ever since Richard Peto had called me a statistical ignoramus over lunch in Oxford in the 1980s I have always been careful to involve statisticians in all our research. And finally, our group is blessed by extraordinarily good IT led by David Perry.

\section{Practical Neurology}

In 1998, we had some bad luck, or maybe we had become overconfident, or maybe I wasn't paying proper attention. Having been funded by the UK Medical Research Council for nearly 20 years, they did not renew our grant. I was so angry, I vowed that I personally would never write another grant application. Luckily the rest of our group did not overreact quite so precipitously and they are all doing very well with all their grants and projects. I determined to put the bad luck to good use and change course a bit - fortunately back in those rather easier days my university either didn't notice or didn't mind. I had always been interested in teaching (not in the modern fashion for medical students to be taught to be nice to patients without having a clue what is wrong with them, a fashion which the students are fortunately well able to rise above to become decent doctors) and in how to translate the primary science which most doctors cannot understand into practical and reliable information to improve their practice. And so I eventually persuaded Blackwells to publish - for a few years before they sold us to the British Medical Journal - a journal which, in a nostalgic nod to Bryan Matthews's classic book of the same name, we called Practical Neurology (http://jnnp.bmj.com/practicalneurology/index.dtl). My research background, public health interest, and maybe politics, too, were all revealed in our mission statement:

- we are deadly serious in our intent to inform and educate and so enhance neurological practice worldwidereflecting the internationalism of medical practice and research; 
- we believe that the common and the treatable are the most important issues in neurology - of course for this readership stroke is at the top;

- we are evidence-based - what else for we who were involved from the very beginning of the Cochrane collaboration;

- we are systematic in our approach to the evidence more Cochrane;

- we are balanced, professional and independent of any sponsoring organisations - so we do not accept articles from public relations consultants, educational companies and the like;

- we believe that neurology is very much a part of medicine, both in hospital and in the community, it is not elitist or separate - a criticism of the old-fashioned British neurologist;

- as expressed in the title of the journal, we take a pragmatic and practical approach which is not technology driven - another criticism, this time of those who believe that all the questions in both clinical practice and research can be answered by yet another brain scan;

- we are allowed to have some fun - always crucial in my view; unless the teachers and students are having fun one doesn't learn anything durable or useful.

\section{My Final Frontier - The Overregulation of Clinical Research}

Finally, what I now perceive to be the most serious battle of all is the battle against the ethicists and regulators who, mostly I suspect without meaning to, are destroying clinical research and so damaging the public health and the care of individual patients. My interest in this area also arose from a chance event when Rustam Al-Shahi Salman in the late 1990s found that his application to the Scottish local research ethics committees for his recordsonly observational study of intracranial vascular malformations required 5,789 A4 pages weighing $27 \mathrm{~kg}$, literally an arm and a leg! And all for a mere three minor modifications of our procedures, and yet this delayed the start of the project for up to 4 months in some places. Since then, the situation has got worse and worse with the proliferation of official UK guidelines which have overinterpreted the legal background enshrined in the Data Protection and Human Rights Acts. This has made it harder and harder to do observational epidemiological research because of the privacy issue, and demands that if one cannot get consent from every patient in a research study (a demand which does not extend to the same methodology

Chances and Battles in Stroke Research but the different badge of audit), one has to anonymise patient data which may be impossible or impractical to achieve. All in the context that in the UK there has never been a successful legal case against breech of confidentiality in a research study. The doctors and researchers have not been bold enough to stand up for clinical research, patients and the public health. This has left the running to the lawyers, ethicists, media commentators and politicians who simply cannot understand how great the problem is. These people need to be educated by empirical examples of how their demands not only hinder research, but also lead to the wrong answers from the research they do allow, and we need our patients and their organisations to help, but again they, too, must understand the problem not in theory but from real examples. So here are three, from the hundreds there must be.

First, in the Scottish Intracranial Vascular Malformation study we were at first allowed to look at the records of patients, but not approach them directly, even if they had not explicitly consented to be in the study. Some could not consent because they were dead or too cognitively damaged, or because their doctors did not want them approached by the study team as they had either not told them the diagnosis, or were trying to allay their anxiety with reassurance about their prognosis. Because the Scottish Multicentre Research Ethics Committee had appreciated that our research was likely to be biased by the exclusion of the patients whose consent we could not obtain, we were able to compare the consenters with the non-consenters [10]. The consenters were more likely to have presented with epilepsy than an intracranial haemorrhage, and were more likely to survive or to have epilepsy during follow-up. So if we had only been allowed to study the consenters, we would have concluded that arteriovenous malformations were not such a serious issue as they clearly are, and this would make any - admittedly unwise - non-randomised comparisons with our patients hopelessly unsound. But, I am afraid the Scottish Multicentre Research Ethics Committee, reflecting changes in the law and in ethics, has recently forbidden our use of patient data without their consent, so the study may have to stop as a result and we will never know what the longterm outcome is for these patients. Is that a proportionate balance between the risks of inadvertent disclosure of patient data versus the public health? I personally don't think so and we should ask the patients what they think.

Second, GALA is a multicentre trial of local versus general anaesthesia for carotid surgery (http://www.dcn. ed.ac.uk/gala/default.asp) and during the pilot phase we 


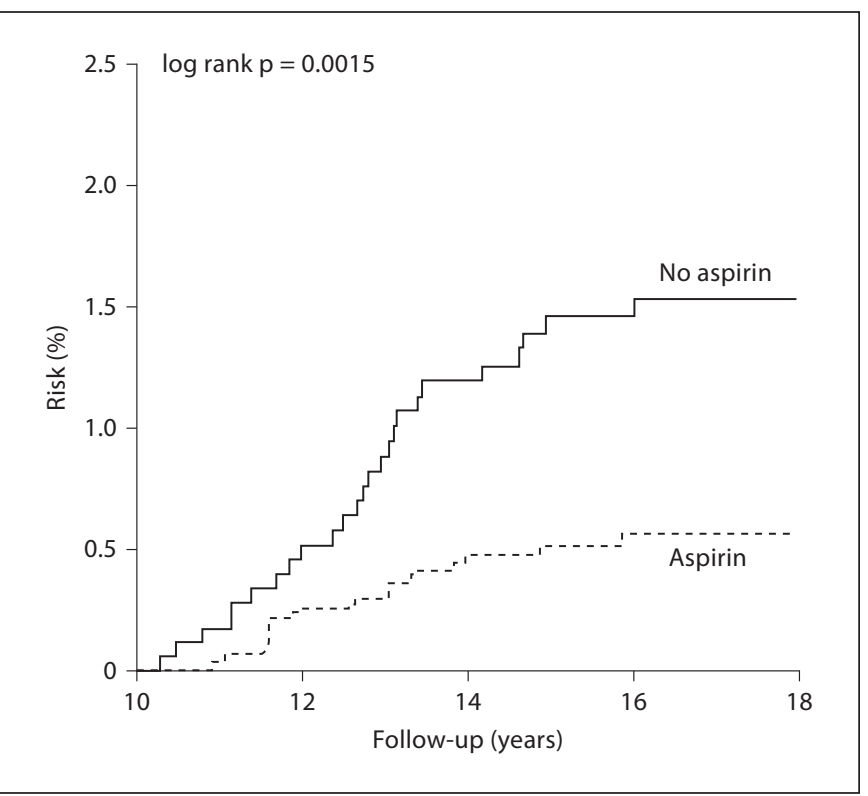

Fig. 6. The effect of aspirin for a few years on the later risk of colorectal cancer in the United Kingdom Transient Ischaemic Attack Aspirin Trial and the British Doctors Aspirin Trial. From [12], reprinted with permission.

were recruiting about 50 patients every 4 months. In the main phase, with far more centres, this increased dramatically to about 150 patients every 4 months. However, we could have recruited far more if we had not had a year of no increased recruitment because after the main phase was funded all the new centres struggled for so long to get ethics and regulatory approval. Is this ethical? We worked out that the sample sizes of the three big trials we are running in Edinburgh could have been 12\% greater, but for these nonsensical delays imposed on us, some hospitals took nearly a year to approve a trial already approved by the appropriate ethics committee [11]. But at least we are still doing clinical research, which is more than can be said for many colleagues who have just given up under the relentless pressure of the ethicists and regulators.

The third example is not about stroke but cancer of the colon, a personal interest as I once had it, so I have much to lose by any attacks on colon cancer clinical research. I have already mentioned that the United Kingdom Transient Ischaemic Attack Aspirin Trial found fewer cancer deaths in the aspirin group, but the follow-up was only for a few years and no particular type of cancer was involved. Years later, because the patients had all been flagged for their death certificates, and could also be linked with the UK Cancer Registries, and the same ap- plied to Richard Doll's primary prevention trial of aspirin in several thousand British Doctors, Pete Rothwell was able to look at cancer outcomes over more than 20 years. However, amazingly, it took him endless applications over 3 years to get access to the relevant data, largely because the patients had not originally consented to have their data looked at in this way, 20 years ago when the rules were different, and bearing in mind that anyway most of them were now dead. The study nearly did not happen so great were the barriers. However, it did and it was found that aspirin reduces the risk of colon cancer, not just adenomatous polyps which we already knew (fig. 6) [12]. While this is not a reason for everyone over the age of 50 to take aspirin, it might be a reason for my children who are at increased risk of colon cancer to take aspirin when they are older - and yet the ethicists and regulators nearly stopped this information emerging. Was this ethical? I think not - as a patient, let alone as a clinical researcher.

\section{Finale}

Enough of this complaining, and time to thank all my friends, mentors and colleagues over the years, many of whom I have mentioned, and to Judi Clarke who has been my ever tolerant and cheerful secretary for the last 17 years. Without them what I have described would not have happened - by chance, deliberately, or in any other way. It is delightful seeing all my younger colleagues in Edinburgh doing so well, particularly with their collaborations in Europe and beyond, so important for world understanding, tolerance and peace. Luck will come their way as it has mine. My advice is to ride the good luck and exploit the bad luck if you can. Play to your strengths and what is possible to do in your health care and research context, others in different contexts will not be able to do what you can. Don't attempt the impossible. Don't make enemies, but if you do avoid them. Above all, enjoy yourselves and have fun, as I have definitely had.

\footnotetext{
References $\quad \square_{1}$ Warlow CP, Hinton P: Early neurological disturbances following relatively minor burns in children. Lancet 1969;ii:978-982.

2 Warlow CP, Ogston D, Douglas AS: Venous thrombosis following strokes. Lancet 1972;i:1305-1306.

3 Ferriar J: An affection of the lymphatic vessels hitherto misunderstood; in Ferriar J (ed): Medical Histories and Reflections. London, Cadell Davies, 1810, vol 3.
} 
4 Beckett S: Murphy. London, Routledge, 1938

5 Warlow CP, Beattie AC, Terry G, Ogston D, Kenmure ACF, Douglas AS: A double-blind trial of low doses of subcutaneous heparin in the prevention of deep vein thrombosis after myocardial infarction. Lancet 1973;ii:934936.

6 United Kingdom Transient Ischaemic Attack (UK-TIA) Aspirin Trial: interim results. UK-TIA Study Group. BMJ 1988;296:316320.
7 Secondary prevention of vascular disease by prolonged antiplatelet therapy. Antiplatelet Trialists' Collaboration. BMJ 1988;296:320331.

8 Warlow CP: Carotid endarterectomy: does it work? Stroke 1984;15:1068-1076.

Rothwell PM, Coull AJ, Giles MF, Howard SC, Silver LE, Bull LM, Gutnikov SA, Edwards P, Mant D, Sackley CM, Farmer A, Sandercock PAG, Dennis MS, Warlow CP, Bamford JM, Anslow P, for the Oxford Vascular Study: Change in stroke incidence, mortality, case-fatality, severity, and risk factors in Oxforsshire, UK from 1981-2004 (Oxford Vascular Study). Lancet 2004;363: 1925-1933.
10 Al-Shahi R, Vousden C, Warlow C, for the Scottish Intracranial Vascular Malformation Study (SIVMS) Steering Committee: Bias from requiring explicit consent from all participants in observational research: prospective, population based study. BMJ 2005; 331:942-945.

11 Al-Shahi Salman R, Brock TM, Dennis MS, Sandercock PAG, White PM, Warlow C: Research governance impediments to clinical trials: a retrospective study. J R Soc Med 2007;100:101-104.

12 Flossman E, Rothwell PM, et al: Effect of aspirin on long-term risk of colorectal cancer. Lancet 2007;369:1603-1613. 